\title{
Large-Scale Atmospheric Dispersal Simulations Identify Likely Airborne Incursion Routes of Wheat Stem Rust Into Ethiopia
}

\author{
M. Meyer, ${ }^{\dagger}$ L. Burgin, M. C. Hort, D. P. Hodson, and C. A. Gilligan ${ }^{\dagger}$
}

First and fifth author: Epidemiology and Modelling Group, Department of Plant Sciences, University of Cambridge, Cambridge, CB2 3EA, U.K.; second and third author: Atmospheric Dispersion and Air Quality (ADAQ), Met Office, Exeter, EX1 3PB, U.K.; and fourth author: International Maize and Wheat Improvement Center (CIMMYT), PO Box 5689, Addis Ababa, Ethiopia.

Accepted for publication 22 May 2017.

\begin{abstract}
In recent years, severe wheat stem rust epidemics hit Ethiopia, sub-Saharan Africa's largest wheat-producing country. These were caused by race TKTTF (Digalu race) of the pathogen Puccinia graminis f. sp. tritici, which, in Ethiopia, was first detected at the beginning of August 2012. We use the incursion of this new pathogen race as a case study to determine likely airborne origins of fungal spores on regional and continental scales by means of a Lagrangian particle dispersion model (LPDM). Two different techniques, LPDM simulations forward and backward in time, are compared. The effects of release altitudes in time-backward simulations and $P$. graminis f. sp. tritici

urediniospore viability functions in time-forward simulations are analyzed. Results suggest Yemen as the most likely origin but, also, point to other possible sources in the Middle East and the East African Rift Valley. This is plausible in light of available field surveys and phylogenetic data on TKTTF isolates from Ethiopia and other countries. Independent of the case involving TKTTF, we assess long-term dispersal trends ( $>10$ years) to obtain quantitative estimates of the risk of exotic $P$. graminis $\mathrm{f}$. sp. tritici spore transport (of any race) into Ethiopia for different 'what-if' scenarios of disease outbreaks in potential source countries in different months of the wheat season.
\end{abstract}

Incursions and subsequent spread of exotic wheat rust races into new wheat growing areas can result in widespread epidemics across landscapes dominated by susceptible cultivars. A better understanding of dispersal patterns, seasonality of dispersal, and identification of likely sources of exotic incursions would greatly improve early warning and preparedness. Novel applications of advanced airborne spore-dispersal modeling on regional and continental scales are described here, in a case study involving recent wheat stem rust incursions into Ethiopia-East Africa's largest wheat-producing country.

The East African Highlands are known for the evolution and survival of new wheat rust races, despite not being an important wheat-growing region globally (Roelfs and Bushnell 1985). The favorable environmental conditions and almost year-round presence of host plants in different areas facilitate the survival and buildup of pathogen populations. The Digalu race (TKTTF) of the causal agent of wheat stem rust, Puccinia graminis $\mathrm{f}$. sp. tritici, was first reported as a new race in Ethiopia in August 2012 (Global Rust Reference Center, Aarhus, Denmark, unpublished data). It then escaped further detection until early October 2013, but by midNovember 2013, a severe epidemic on the most widely grown wheat variety (Digalu) had started. An approximate area of 20,000 to 40,000 hectares was affected by wheat stem rust in the 2013 epidemic (Olivera et al. 2015). And in 2014, despite improved early warning, thousands of hectares were again lost to a localized epidemic (Singh et al. 2015). The most recent data from 2016 indicate that $>90 \%$ of all stem rust samples collected in Ethiopia and pathotyped are race TKTTF. Since, in Ethiopia, wheat is cultivated by $\sim 5$ million households on $\sim 1.7$ million hectares, yield losses caused by TKTTF can have direct consequences for the livelihoods of a large number of agricultural stakeholders.

In most of Ethiopia, rainfed wheat is grown by smallholder farmers with an average field size of about 1 hectare during the

†Corresponding authors: M. Meyer; E-mail: mm2086@cam.ac.uk, and C. A. Gilligan; E-mail: cag1@cam.ac.uk

(C) 2017 The American Phytopathological Society second, longer rainy (meher) season that usually starts in June or July and lasts until December or January (Gebre-Mariam et al. 1991; White et al. 2001). In some areas, as, for example, parts of the Bale zone of Ethiopia, where TKTTF was first detected, wheat is also grown in the preceeding short rain (belg) season, from March or April to June or July. In the Bale zone, the environment is suitable for infection almost year around. Prior to detection in the Bale zone in 2012, race TKTTF was first reported in Turkey in 2008 (Mert et al. 2012) and in 2010 in Iran. In subsequent years, the same race was detected in several countries in the Middle East (Table 1). In the East African Rift Valley zone, TKTTF was first detected in Ethiopia and Sudan in 2012 and, subsequently, also in other countries (Table 1). The available evidence, therefore, indicates that race TKTTF had a putatitive origin in the Middle East but is spreading over a wider geographical range that now includes East Africa.

It has been shown that TKTTF isolates from Ethiopia are not recent mutations from common $P$. graminis f. sp. tritici races in Ethiopia (Olivera et al. 2015). Human-mediated transport of TKTTF into Ethiopia cannot be unequivocally ruled out, but it is less likely than airborne incursion. The most recent phylogentic analyses show that Ethiopian isolates of TKTTF fall within the same genetic clade (IV-A.1) as TKTTF isolates from Turkey, Egypt, Lebanon, Georgia, Azerbaijan, Israel, Iran, Yemen, and Sudan (L. Szabo, unpublished). Detection of genetically related isolates across several countries within a common geographic region would suggest airborne dispersal rather than human-mediated transport. In addition, the site of first detection of TKTTF in Ethiopia was a relatively remote rural area (over $100 \mathrm{~km}$ from the nearest asphalt road) and detection occurred during the low season for foreign visitors (i.e., the Ethiopian rainy season). Airborne spore dispersal is the key mode of dispersal of wheat rusts. In the Bale zone, where TKTTF was first detected, wheat is mostly grown at $>2,000 \mathrm{~m}$ above sea level, in the highlands on the southern side of the continental-scale East African Rift Valley. The topography of the Rift Valley can lead to the funneling and effective turbulent mixing of air masses, in particular from the northeast, on the wheat-producing regions in the Bale zone. Both, dry deposition of $P$. graminis f. sp. tritici urediniospore (hereafter also referred 
to as "spores") from near-surface air masses as well as wet deposition by rain could have caused the incursion of race TKTTF. Strong convective air motions in the entire region during the northern summer months (June to September), when the intertropical convergence zone (ITCZ) migrates over the Horn of Africa, enhance the probability of the uplifting of spores with consequent long-distance airborne pathogen transport. Given these circumstances, the focus of this study is to analyze the evidence for long-distance aerial incursion.

The incursion of TKTTF into the wheat-producing areas of Ethiopia led to devastating epidemics, largely because areas of approximately $500 \times 10^{3}$ hectares were planted with only one wheat variety, 'Digalu', which is susceptible to TKTTF. The widespread deployment of 'Digalu' was originally motivated by its resistance against prevalent stripe rust races as well as against the Ug99 race group of P. graminis f. sp. tritici (Olivera et al. 2015; Singh et al. 2015). However, the incursion of TKTTF into Ethiopia in the years immediately after the distribution of the Digalu wheat variety underlines that large-scale deployment of single varieties with major gene resistance can have devastating consequences when facing long-distance incursion of virulent pathogen races. Breeding strategies should, therefore, be complemented by other measures; effective surveillance for early warning, targeted spraying of fungicides, and pre-emptive replacement of varieties would all benefit from enhanced understanding and prediction of long-distance airborne pathways of fungal spores.

For our analysis of likely airborne incursion routes of spores into Ethiopia, we use a combination of Lagrangian particle dispersion modeling (LPDM), finely-resolved global meteorological data, high-performance computational resources, and information about wheat distribution and growing patterns throughout East Africa and the Middle East. We address the following key questions:

(i) What is the likely airborne origin of the wheat stem rust race TKTTF that invaded Ethiopian wheat fields?

(ii) Are there seasonal differences in likely airborne incursion routes?

(iii) How are inferences about the likely origins of race TKTTF into Ethiopia affected by assumptions concerning different release altitudes in time-backward simulations and different functional forms of spore viability in time-forward simulations?

(iv) Independent of the case of incursion of TKTTF, can we derive quantitative estimates of the risk of airborne incursion of spores from neighboring countries to Ethiopia that may serve as directly useful information for the development of sampling and control strategies?

\section{MATERIALS AND METHODS}

Wheat production and field disease survey data. With the development of the global wheat rust monitoring system about 10 years ago (CIMMYT Rusttracker), surveillance efforts have greatly increased and improved our understanding of wheat rust race distributions, especially in Ethiopia and Kenya but, also, in other countries of the East African Rift Valley zone. However, survey data from some important potential source countries of TKTTF in Ethiopia, for example, Yemen, are still very limited. We bring together available disease survey data (CIMMYT Rusttracker; Singh et al. 2015), with wheat production data (FAO GIEWS country briefs; FAOSTAT, and MapSPAM databases) and gather information on wheat areas, wheat production, typical seasonal timing of wheat stem rust, and years of first detection of race TKTTF in countries in East Africa and the Middle East (Table 1).

Likely time windows of first incursion of TKTTF into Ethiopia. Race TKTTF was first detected in Ethiopia, at trace levels, from a farmers field in Afrisha, in the Bale zone, in August 2012 (longitude 40.59, latitude 7.19; Global Rust Reference Center, and unpublished). As race TKTTF was not previously detected in Ethiopia, despite regular field surveys (approximately 1,000 survey entries per year and associated representative sampling), it is feasible that Afrisha is one of the initial incursion locations. Given the uncertainty around this assumption, we note that the results below are not sensitive to small changes of the coordinates of the first detection site, as we study airborne incursion on regional and continental scales (500 to $3,000 \mathrm{~km}$ ). The site of first detection is used here as a representative site of one of the main wheat areas in southern Ethiopia; the Bale zone is critically important for stem rust epidemiology in Ethiopia. It is one of the main belg season

TABLE 1. Wheat production, seasonal timing of wheat stem rust, and years of first detection of race TKTTF (Digalu) in the Middle East and the East African Rift Valley ${ }^{\mathrm{a}}$

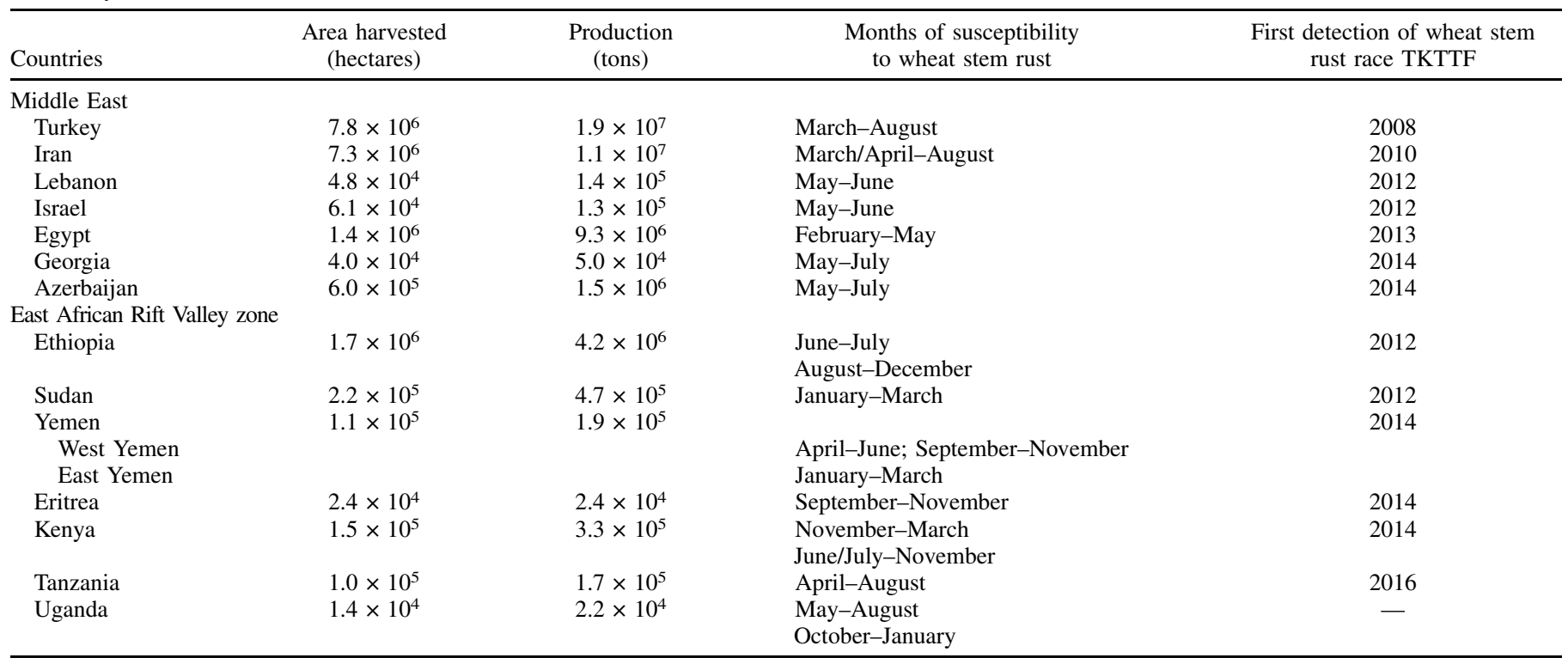

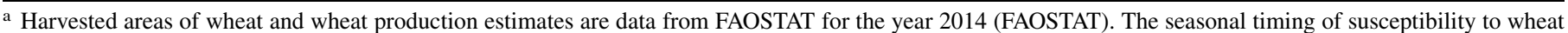
stem rust indicates those months when wheat stem rust typically occurs in the main national wheat growing areas. The timing is obtained by consultation of field pathologists in different countries and FAO crop calendars (FAO GIEWS country briefs). In some countries there is a large diversity of wheat-growing practices, and here, we summarize key months on main wheat areas. Years of first detection of TKTTF are obtained from Mert et al. (2012), Singh et al. (2015), CIMMYT Rusttracker (2017), and L. Szabo (personal communication). In Turkey, related races had already occurred in the 1990s. 
wheat-growing areas, where stem rust is often first reported. It can act as a green bridge and inoculum source for the main meher season. The case study around incursion of TKTTF to the Bale zone is, therefore, of relevance for the wider stem rust epidemiology and risk in Ethiopia.

The first detection in Afrisha, in the Bale zone, dates back to August 6, 2012. This date does not allow direct inferences about the actual day of incursion of the pathogen, because no complete timeseries of race-specific disease sampling data are available. However, as regular surveys are conducted in Ethiopia and TKTTF was highly virulant to the predominant wheat varieties grown in the years prior to detection, it is likely that TKTTF was dispersed into Ethiopia either during the minor season in which it was first detected or during the preceding main wheat season in 2011. In the absence of field data on the exact incursion time, we study airborne transport on the set of all days during two incursion time-windows, i.e., June and July 2012 (belg season of the year of incursion) and August to December 2011 (prior meher season).

Numerical Atmospheric-Dispersion Modelling Environment (NAME). Airborne spore dispersal during potential incursion time windows is studied using NAME, the LPDM developed by the United Kingdom's Met Office (Jones 2013; Jones et al. 2007). NAME has been validated in numerous studies, as, for example, with volcanic ash particulates (Webster et al. 2012). It is used in the United Kingdom for national emergency response simulations for chemical and nuclear accidents, including the Fukushima disaster (Draxler et al. 2015). NAME is also an important tool to predict infection risks of airborne livestock diseases, such as foot-and-mouth and bluetongue (Burgin et al. 2013). As a state-ofthe-art LPDM, it constructs a three-dimensional representation of the atmosphere, based on off-line gridded meteorological datasets, and simulates release, turbulent atmospheric dispersal, loss of viability, and deposition of spores. We use the global archive data from the Met Office Unified Model as meteorological input to the dispersion simulations (Davies et al. 2005; Jones 2013; Jones et al. 2007). These data contain, for example, spatio-temporally varying, three-dimensional wind fields, pressure fields, temperature fields, as well as cloud-cover and precipitation rates. The datasets for the years of likely incursion of TKTTF, 2011 and 2012, have a temporal resolution of $3 \mathrm{~h}$, a horizontal spatial resolution of $\sim 25 \mathrm{~km}$, and 59 vertical layers (extending to $29 \mathrm{~km}$ altitude). The datasets used for the assessment of long-term trends of dispersion into Ethiopia (2003 to 2016) change in spatial resolution from $\sim 60 \mathrm{~km}$ in 2003 to $\sim 17 \mathrm{~km}$ in 2016 . Release and turbulent dispersal of $P$. graminis $\mathrm{f}$. sp. tritici urediniospores is simulated by calculating three-dimensional stochastic trajectories of large numbers of simulation particles in such a way that the overall simulation particle ensemble approximates the three-dimensional transport of real-life $P$. graminis f. sp. tritici urediniospores in the atmospheric flow. The turbulence parameterization in NAME takes into consideration both the effect of small-scale eddies (with time scales of the order of the simulation particle time step of about 1 to $10 \mathrm{~min}$ ) and meso-scale eddies (with time-scales between the simulation particle time-step and the resolution of the meteorological data, i.e., about 10 to $180 \mathrm{~min}$ ). Viability of spores during transport is accounted for and spore transport to the ground is simulated explicitly by calculating gravitational settling, dry deposition, and wet deposition. The specifics of the parameterization used in time-backward and timeforward simulations in this study are given in the following paragraphs. Full details about the dispersion environment of NAME are given by Jones et al. (2007) and Jones (2013).

Time-backward simulations from the site of first detection. NAME can be used to model the history of air masses arriving at a given receptor location and time. For this analysis the threedimensional stochastic trajectories of simulation tracer particles are numerically calculated backward in time, moving in the opposite direction of prevailing winds, while representing the effect of turbulence statistically by the diffusive behavior of the stochastic tracer-ensemble. As a result, one obtains an air-history map of likely air concentration of tracer particles during the days before arrival, indicating from where air masses have most likely been transported to the receptor (see Jones [2013], for details of the backward mode). In time-backward simulations, loss of viability of spores as well as spore deposition cannot be explicitly accounted for (Jones 2013). Therefore, one has to assume a certain release altitude for tracer particles, to represent the altitude from which spores may have been deposited (by dry or wet deposition) on the site of first detection. Instead of assuming a single representative release altitude, as used in previous studies (Fernández-Rodríguez et al. 2015; Grinn-Gofroń et al. 2016; Sadyś et al. 2014; Schmale and Ross 2015; Skjøth et al. 2009), here, we consider a set of different release altitudes. Every day of the likely incursion time windows, we release $10^{6}$ model tracer particles from each of the following altitudes in the vertical atmospheric column above the site of first detection: 1, 500, 1,000, 1,500, 2,000, 2,500, $3,000,3,500,4,000,5,000,6,000,7,000,8,000,9,000,10,000$ meters above surface. This choice, including very high altitudes, is motivated by strong convective activity and formation of high clouds (up to approximately $12 \mathrm{~km}$ ) above Ethiopia in July to September, which implies that spores could, theoretically, be transported and rained-out from these heights. Given the plausible assumption that the number of transported spores and spore viability decrease with increasing altitudes in the atmosphere and in the absence of empirical data from Ethiopia, we give most attention to altitudes of 1 to 3,000 $\mathrm{m}$ above the surface, in analyzing our results. In all time-backward simulations, the maximum travel time of tracer particles is set to 3 days, chosen to estimate the survival times of $P g t$ urediniospores reported in field experiments of Maddison and Manners (1972).

Time-forward simulations to the site of first detection. We simulate dispersal from a large number $(>300)$ of potential source locations forward in time to the site of first detection. This allows us to simulate the loss of spore viability as well as different deposition mechanisms explicitly. A grid of potential source locations is used covering wheat areas (MapSPAM database) in the East African Rift Valley, the Arabian Pensinsula, and the southern regions of the Middle East. Additionally, we choose one representative source location in other potentially important source countries further away, for example, Turkey, to test the feasibility of direct spore transport from these countries to the region of first detection of TKTTF. From each of the potential source locations, we simulate daily spore release, turbulent transport, loss of viability, and deposition of spores on the site of first detection. In an additional analysis, we choose a small set of key sources and simulate long-term dispersal trends $(>10$ years), to obtain estimates of typical dispersal frequencies and amounts from other countries to the Bale zone in Ethiopia during different months of the wheat season for different outbreak scenarios at potential sources. For the time-forward simulations, we use and extend a parametrization that was tested in previous work (Olivera et al. 2015). For details of the dispersion modeling environment NAME, please refer to Jones (2013). In this paper, we introduce a new UV decay scheme and briefly summarize the key parameterization for spore dispersal used in this study.

Source extent. All source locations in the LPDM simulations are defined with a spatial extent of $20 \times 20 \mathrm{~km}$, chosen to represent an arrangement of wheat fields from which spores can be released.

Source-strength. For the simulations from a large array of potential source locations, we set the source strength of all sources to a constant of 1 (spore material/source location/day) and restrict our analyses to the relative contribution of different sources to spore deposition on the site of first detection. For the analysis of long-term trends of spore dispersal into Ethiopia, we estimate real-life spore canopy escape rates for four different 'what if' disease scenarios.

Release timing. Spore release is simulated daily from 09:00 to 15:00 local time.

Turbulent dispersal. Simulation particles with density and diameter of $P$. graminis f. sp. tritici urediniospores are advected stochastically in three dimensions. We account for turbulence 
by tracing trajectories of $10^{6}$ simulation particles per day and per source. This allows a robust treatment of the effect of mean and turbulent wind variations. Small-scale turbulence and mesoscale eddies are accounted for and the diffusive long-range scheme is used with a time-step of 5 to $15 \mathrm{~min}$, adapted to the resolution of the meteorological input data. Deep convection is simulated.

Spore viability. Particular attention is given to spore viability during transport, as it is one of the key subprocesses of longdistance dispersal of fungal pathogens. In other published work, long-distance $P$. graminis f. sp. tritici spore dispersal was modeled by setting a maximum time of 3 days for the calculation of mean trajectories, but the actual proportion of spores remaining viable during atmospheric transport was not modeled (Singh et al. 2011). Here, we assume that UV radiation is the key limiting factor of spore survival (Maddison and Manners 1972) and explicitly model two different functional forms of the loss of viable spore material during atmospheric transport, denoted as: model variant 1, exponential decay as a function of time and model variant 2 , exponential decay as a function of UV dose. In case 1, of exponential decay in time, $t$, the proportion of viable spore material, $m(t)$, associated with every simulation particle decays according to $m(t)=m_{o} \exp (-\lambda \mathrm{t})$, where $m_{o}$ describes the initial spore material at release. We assume a maximum spore lifetime of $t_{\max }=3$ days and determine the value of $\lambda$ such that, after $72 \mathrm{~h}$ of transport, the proportion of viable spores is reduced to $1 \%$, at which time we take particles out of the simulation. This choice is made to approximate results from field experiments; Maddison and Manners (1972) report that, after $20 \mathrm{~h}$ of sunshine, approximately $10 \%$ of $P$. graminis f. sp. tritici spores remain viable for germination. Assuming that, on average, spores experience a comparable dose of solar radiation approximately half of their travel time (day and night), our choice of $\lambda$ yields approximately $10 \%$ of viable spores after $20 \mathrm{~h}$ of sunshine, corresponding to $40 \mathrm{~h}$ of dispersal. We also assess the sensitivity of results to a longer maximum spore lifetime of $t^{\prime}{ }_{\text {max }}=5$. In the case of model variant 2 with UV dose-dependent decay, the proportion of viable spore material associated with each simulation particle is computed as $m(t)=m_{o} \exp (-s D)$, where $s(t)$ denotes the sensitivity of $P$. graminis f. sp. tritici spores to UV dose and $D(t)$ denotes the UV dose $\left(\mathrm{MJ} / \mathrm{m}^{2}\right)$ experienced by each simulation particle from release until time $t$. Experimental work shows that, at high ambient relative humidities, the sensitivity of $P$. graminis f. sp. tritici spores to UV radiation sharply increases (Schwinghamer 1958). To account for this, we calculate the sensitivity of $P$. graminis $\mathrm{f}$. $\mathrm{sp}$. tritici spores as $s(t)=\varepsilon k$, where $k$ is a $P$. graminis $\mathrm{f}$. sp. tritici spore characteristic constant sensitivity, and we introduce a simple scaling factor, $\varepsilon(t)$, that depends on ambient relative humidity during atmospheric transport. We set $\varepsilon(t)=1$ for low and moderate relative humidities and $\varepsilon(t)=2$ for high $(>90 \%)$ relative humidities, defined in accordance with the approximate doubling of sensitivity observed in Schwinghamer (1958). The value of $k=1.1$ is obtained from the survival curves reported in field experiments (Maddison and Manners 1972) and an approximate cumulative UV dose (2.14 $\left[\mathrm{MJ} / \mathrm{m}^{2}\right]$ ) for the hours and cloud conditions during the three days of the experiment, August 23-25, 1968. We set the maximum lifetime of spores to $t_{\max }=3$, and assess sensitivity of results to an alternative maximum lifetime $t^{\prime}{ }_{\text {max }}=5$.

The approximate UV dose experienced by each simulation particle during each time step, $\Delta t$, is calculated as $\Delta D=I_{\mathrm{uv}} \cos \left(\phi_{z e n}\right) \mathrm{C} H \Delta t$, and the fraction of viable spore material at time, $t$, is then determined from the cumulative dose, $D(t)$, along the trajectory of each simulation particle. We define $I_{\mathrm{uv}}=$ const. $=1,360 \times 0.05 \times 0.8 \approx$ $55\left[\mathrm{~W} / \mathrm{m}^{2}\right]$ as the approximate global UV radiation at the top of the cloud layer, obtained from the solar constant, 1,360 [W/m²], by assuming a constant proportion of $5 \%$ of (UV-A + UV-B) radiation (Foyo-Moreno et al. 1999), and a global reduction of total solar radiation by $20 \%$ due to absorption or reflection from the top of the atmosphere to the top of the cloud layer. This form is chosen in accordance with the approximation implemented for broadband surface solar radiation in the dispersion model HYSPLIT (Draxler and Hess 1997), but here, we adapt it to approximate UV radiation at the three-dimensionial position of each simulation particle. We approximate the UV dose at the position of each simulation particle by scaling of $I_{\mathrm{uv}}$ with: (a) the solar zenith angle at the position of each simulation particle $\left(\cos \left[\phi_{z e n}\right]\right)$ to account for the latitudinal and longitudinal position of the sun; (b) a simple empirical cloud correction factor, $C(t)=1.06-0.51 f(t)$, as obtained by Frederick and Steele (1995), with fractional cloud cover $f(t)$ here obtained from the meteorological input data at the position of each simulation particle; and (c) a global altitude correction factor of $\mathrm{H}=12.5 \%$ increase of UV dose per kilometer altitude (above sea level) of simulation particles. The altitude correction is obtained as the mean of all experimental values in the review by Calbó et al. (2005). The plausibility of our UV dose approximation was confirmed in two proof-of-concept tests, comparing our UV approximation with (a) the UV dose computed for the day and location of one of the experiments by Maddison and Manners (1972), using the complex radiative transfer model SPCTRAL2, as published by Kim and Beresford (2008) and (b) comparing the UV dose experienced along trajectories of simulation particles in NAME test simulations with the threedimensional, mechanistically computed, global UV dose obtained from a test run of the Met Office's Unified Model.

Spore deposition. We explicitly simulate the transport of spore material from the atmosphere to the surface by sedimentation, both dry and wet deposition of spores, and add these up to obtain total spore deposition (spore material per area per day) as the result of the time-forward LPDM simulations. Gravitational sedimination of spores is calculated based on structural characteristics of $P$. graminis f. sp. tritici urediospores (density, $\rho=1\left[\mathrm{~g} / \mathrm{cm}^{3}\right]$, from Orr and Trippets (1972); diameter, $\mathrm{d}=26.4[\mu \mathrm{m}]$, from Eversmeyer and Kramer (2000), assuming spherical particles). Dry deposition simulates transport of spores from the lowest atmospheric layer directly to the surface by wind. And the wet deposition scheme uses precipitation rates and cloud data at the position of each simulation particle to compute rain and washout of spores, distinguishing between below cloud washout, convective in-cloud rainout, and dynamic in-cloud rainout (we use the default scavenging coefficients recommended for small particulates [Jones 2013]).

Computational resources. The scale of the data-driven dispersal modeling described in this paper requires high-performace computational resources. The LPDM simulations were conducted on the computing cluster of the Epidemiology and Modeling Group in Cambridge, consisting of 20 machines (Intel Xeon E5-2650; each with 128 GB RAM, 16 cores, 20 MB SmartCache, $2 \mathrm{GHz}$ processor base frequency, and approximately 7 TB disk space). The simulations required about $11 \mathrm{~TB}$ of meteorological input data.

\section{RESULTS}

We firstly describe results indicating likely origins of TKTTF and then show long-term trends of simulated $P$. graminis f. sp. tritici spore dispersal to obtain estimates of the risk of incursion of pathogens from neighboring countries to the Bale zone in Ethiopia in different months of the wheat season.

Likely origin of TKTTF in Ethiopia. History of air masses arriving at the site of first detection. From the LPDM backward simulations, we obtain daily "air history" maps, which show the air concentration of tracer particles in the days before release, indicating where air masses transporting spores have come from. As it is unknown on which day the incursion event happened, we aggregate the daily air-history maps to obtain the cumulative monthly air history for each month (and release altitude). The monthly results indicate two distinct seasonal regimes of the predominant direction of airborne inflow of $P$. graminis f. sp. tritici spores into Ethiopia (Figs. 1 and 2). We summarize these as the belg-season inflow regime (Fig. 1) and the meher-season inflow regime (Fig. 2). 
In the case of a first incursion of TKTTF during the belg season (e.g., June 2012 [Fig. 1]), backward simulations indicate two dominant directions of incursion. Air masses at low altitudes from surface level up to $1.5 \mathrm{~km}$ above ground are most likely to have come from the south (particularly southern Ethiopia and Kenya). Air masses passing the site of first detection at higher altitudes of around 2 to $5 \mathrm{~km}$ predominantly originate from northern and northeastern regions, i.e., from the atmosphere above the countries of Yemen, Eritrea, Sudan, Saudi Arabia, Egypt, Iraq, and Iran (Fig. 1, up to $3 \mathrm{~km}$ ). As there are large differences in the dominant direction of winds at different altitudes that are all in a plausible range for spore transport and deposition, one can only draw very limited inferences about more likely directions of origin of TKTTF for this incursion time window from time-backward simulations.

In the case of incursion during the meher season (October to December 2011) (Fig. 2), the air-history maps indicate that air masses at all tested altitudes from 1 to $4,000 \mathrm{~m}$ predominantly originate from the northeast (Fig. 2). During those months, trade winds blow from the northeast over Ethiopia into the low-pressure field of the ITCZ, at this time located in the southern parts of the Rift Valley. In this case, backward simulations strongly indicate that the likely origin of spores are countries to the northeast of Ethiopia, particularly Yemen and, to a lesser extent, Eritrea.

Spore deposition on the site of first detection from a large array of potential source locations. To overcome limitations of backward simulations and to account explicitly for the loss of spore viability during transport as well as for different deposition processes, we simulate forward-in-time spore dispersal from a large set of possible source-locations to the site of first detection (for each day of the likely incursion time windows). In the absence of empirical field data, we define the same constant daily source strength for all potential sources and analyze, in relative terms, which potential sources contribute more (or less) to deposition on the site of first detection. For all simulations in this section, we assume a timedependent, exponential decay of spore viability with a maximum lifetime of three days. An example of one of the resulting daily deposition plumes is illustrated in Figure 3A. We summarize spore transmission from all potential sources onto wheat fields in a target area of $30 \times 30 \mathrm{~km}$ around the first detection site by analyzing the monthly mean relative contribution of each potential source to spore deposition on the site of first detection.

We first analyze from which potential source locations any airborne transport to the site of first detection could have occurred if there were an outbreak at the sources. This allows a sketch of the geographical area that may influence the pathogen population around the first detection site, given the potential of the atmospheric flow regime to transport spores over long distances (Fig. 3B and C). The extent of the area that could potentially contribute to deposition on the site of first detection is much larger (by approximately $1,500 \mathrm{~km}$ in the north) in June than it is in November (Fig. 3B and C, black circles), indicating a greater potential risk for spore incursion in June. Transferring the concept of a basin (or 'area of catchment')

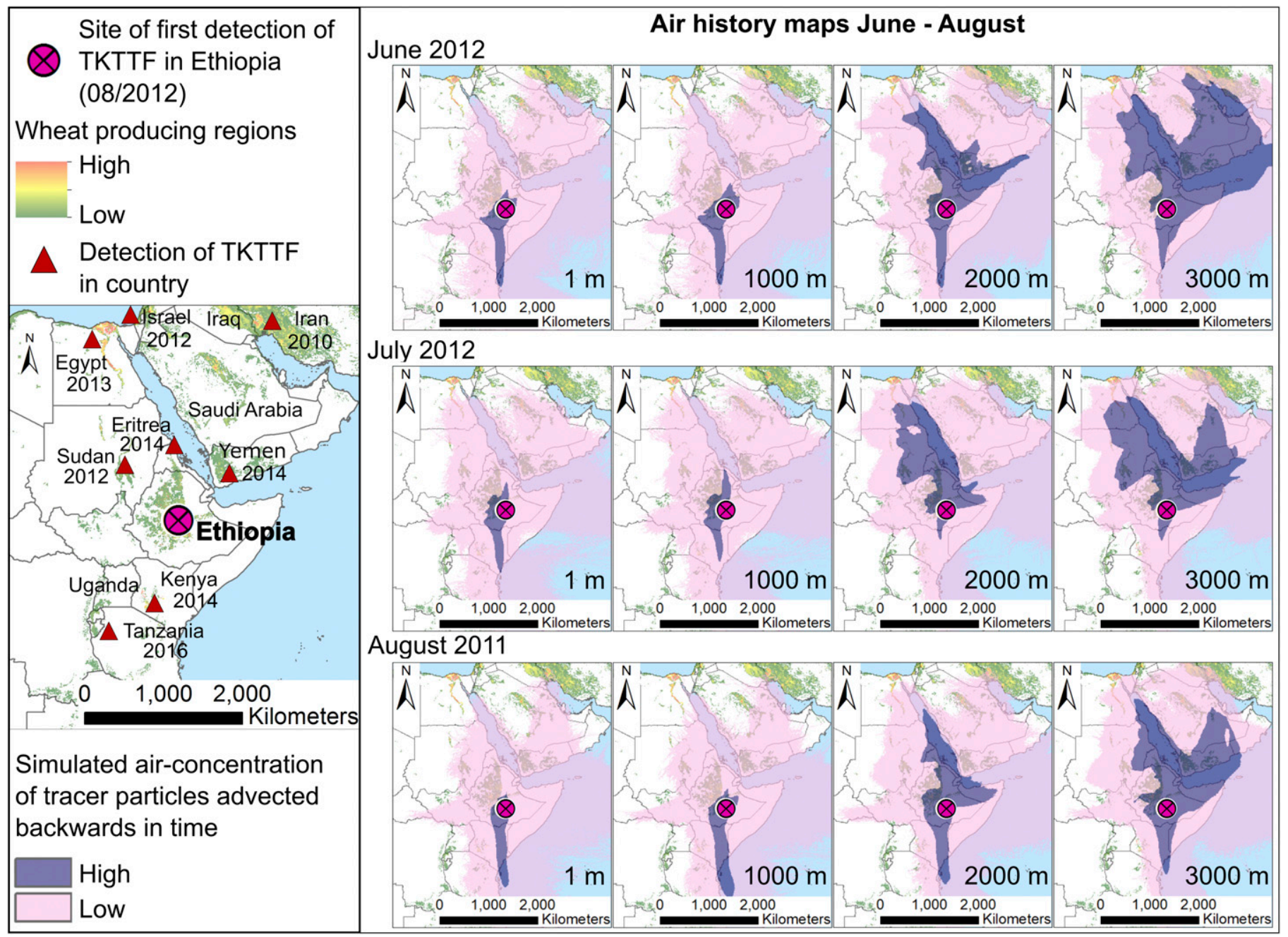

Fig. 1. Inflow of air masses into the vertical atmospheric column above the site of first detection of TKTTF at the end of the belg wheat season in Ethiopia. Illustrated are cumulative monthly air-history maps for a selection of release altitudes (given at the bottom of each map). The daily release rate of tracer material in time-backward simulations is set to a constant, and the resulting tracer concentration is classified into high and low to indicate, in relative terms, more likely source regions of air masses that could have transported TKTTF spores to the site of first detection. 
in hydrology to airborne inflow of pathogens, we introduce the term "airborne catchment area," to delineate the geographic area from which airborne spore transport to a target site (here, the site of first detection) can occur if there is an outbreak at the sources. Note that we draw an analogy to a basin in hydrology here only in qualitative terms to highlight that, despite high daily variations in atmospheric flows, there are seasonal flow regimes that yield simulated spore transport patterns that are consistent, to a certain degree, over time scales of several months.

In all subsequent analyses, we assume that spore dispersal from source locations to the first detection site is restricted, not only to the spatial distribution of wheat areas (as described above) but, additionally, to those times of the year (months) when the main wheat seasons on the main wheat-producing areas overlap in Ethiopia and potential other source countries. This allows further narrowing of likely origins of TKTTF. Our analyses indicate three potential source regions for a possible incursion to Ethiopia during the belg season (Fig. 3D, June 2012). The candidates are (i) Kenya and northern Tanzania, (ii) Yemen and eastern Somalia, and (iii) southern Iraq and Iran. The majority of sources with high contribution are located in Yemen, but the results are not sufficiently distinct to reject the other two candidate sources. Additional simulations over 12-years (2003 to 2014) from one source location in southern Iran show that there was a peak in simulated spore transport from Iran directly into Ethiopia during 2012, the year of first detection of TKTTF. However, the relative contribution from sources in Iran is very low, compared with other potential sources in close geographic proximity (especially Yemen but also Kenya and Tanzania). The results for July 2012 (and August 2011) indicate a comparable pattern of atmospheric transport to the one illustrated in Figure 3D.

If race TKTTF had been transported into Ethiopia in the meher season prior to detection (Fig. 3E, November 2011), simulations show spore transmission from sources in Yemen, Somalia, Eritrea, as well as a small contribution from Kenya. Sources with highest contribution are in Yemen, followed by Eritrea (Fig. 3E). The results for September, October, and December 2011 are similar to those illustrated here for November 2011, with the exception that, by December, wheat is mostly harvested in Yemen and Eritrea, so that incursion from September to November is more likely. We find no direct airborne transport from Turkey, Georgia, or Lebanon (countries where TKTTF has also been detected) in simulations with a maximum spore lifetime of 3 days.

Sensitivity of results to the functional form of spore viability during transport. Spore viability during transport is one of the key parameters of atmospheric dispersal simulations, but, in the case of dispersal from a likely source in West Yemen to the site of first detection of TKTTF in Ethiopia, we find that the differences between a simple, time-dependent viability scheme and a more complex, UV dose-dependent scheme are small (about one order of magnitude) compared with the overall range of deposition amounts (about eight orders of magnitude) (Fig. 4). Also, for this case of spore transport over distances of about $900 \mathrm{~km}$, differences between

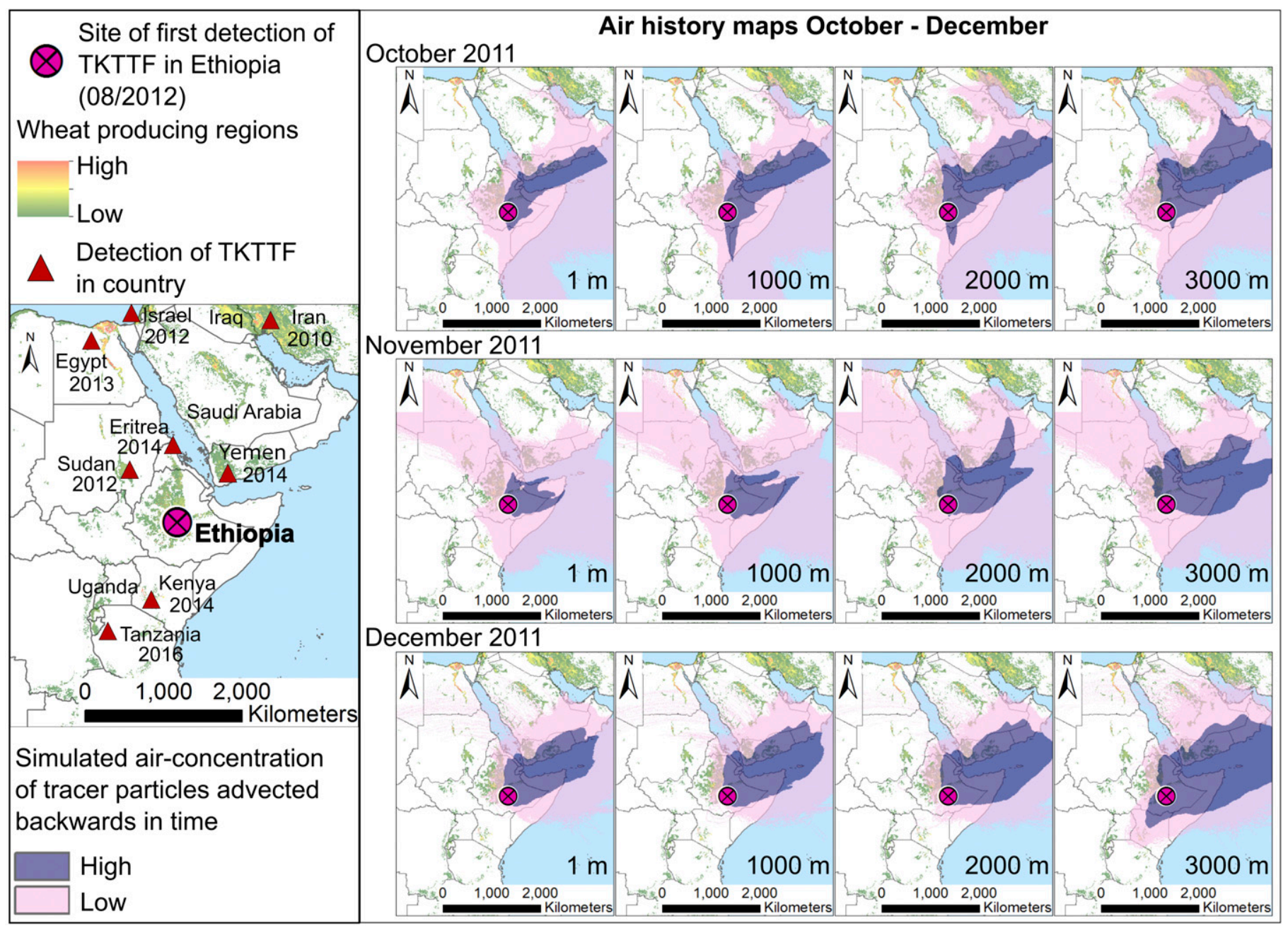

Fig. 2. Inflow of air masses into the vertical atmospheric column above the site of first detection of TKTTF in the meher wheat season. Illustrated are cumulative monthly air-history maps for a selection of release heights (given at the bottom of each map). The daily release rate of tracer material in the time-backward simulations is set to a constant, and the resulting tracer concentration is classified into high and low to indicate, in relative terms, more likely source regions of air masses that could have transported TKTTF spores to the site of first detection. 
3 and 5 days for maximum lifetimes of spores are mostly negligible, since most spores are deposited within the first 3 days. The maximum lifetime of spores has a strong effect, however, on the maximum distance of possible sources (e.g., on the boundaries of the airborne catchment areas [Fig. 3B and C]).

A similar analysis of the effect of different viability schemes on deposition amounts on the site of first detection, as illustrated in Figure 4 for the source in West Yemen, for a selection of further key potential sources (Eritrea, Tanzania, Kenya) shows that the effect of UV-dependent decay is of comparable order (up to about one order of magnitude difference between the UV and the time-dependent scheme). As the contribution to deposition from different sources to the site of first detection (Fig. 3) varies up to 20 orders of magnitude between different sources, one can expect that the identification of Yemen as the most likely source region of TKTTF remains unchanged in simulations with a more complex, UV dose-dependent viability model; the effects of wind, turbulence, and precipitation on spore transport and deposition patterns dominates the ranking of more and less likely source regions in this case. In the following section, we use the UV dose-dependent decay scheme in simulations to determine order of magnitude estimates of the numbers of viable spores that are transported from source countries to the Bale zone in Ethiopia.

Long-term dispersal trends to the Bale zone in Ethiopia. In previous sections, we have analyzed airborne spore transport to the site of first detection in the Bale zone, Ethiopia, for the likely time interval of incursion of race TKTTF (2011 to 2012). In this section, we extend our analysis to a longer time period (2003 to 2016) to analyze trends of simulated airborne spore dispersal to the site of first detection, which we use here as a representative site of one of the key wheat-producing regions in Ethiopia, the Bale zone. We choose a small set of sources in wheat-producing countries that we identify as potential sources in previous sections (Fig. 3). This allows us to obtain quantitative estimates of the risk of exotic $P$. graminis f. sp. tritici spore incursion from other countries to the Bale zone, Ethiopia, in different months of the wheat growing season.

We simulate daily spore dispersal for all months of overlapping main wheat stem rust seasons (Table 1) in source and target country over 14
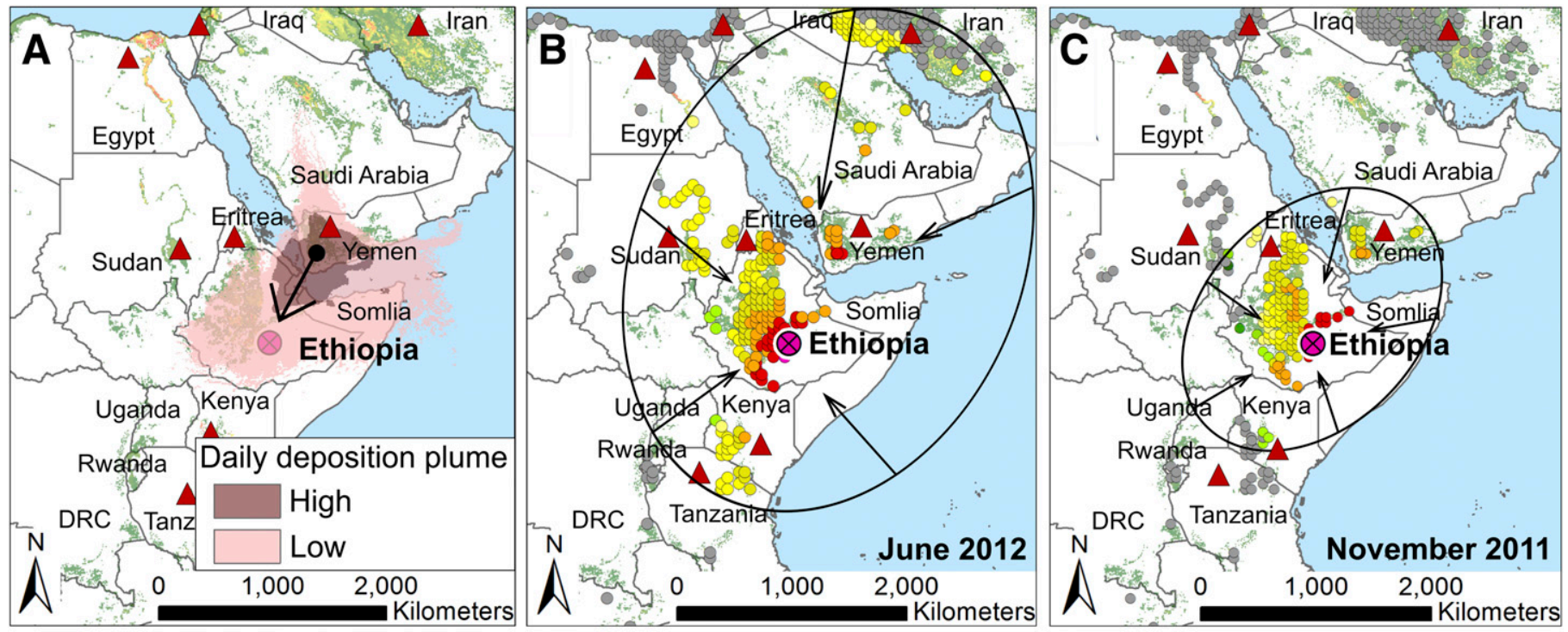

Wheat producing regions
High
Low
Detection of TKTTF
in country
Site of first detection of TKTTF
in Ethiopia (08/2012)
Airborne Pgt-spore
catchment area
deposition on the site of first
detection from potential sources
High $\bigcirc \bigcirc \bigcirc$ Low None
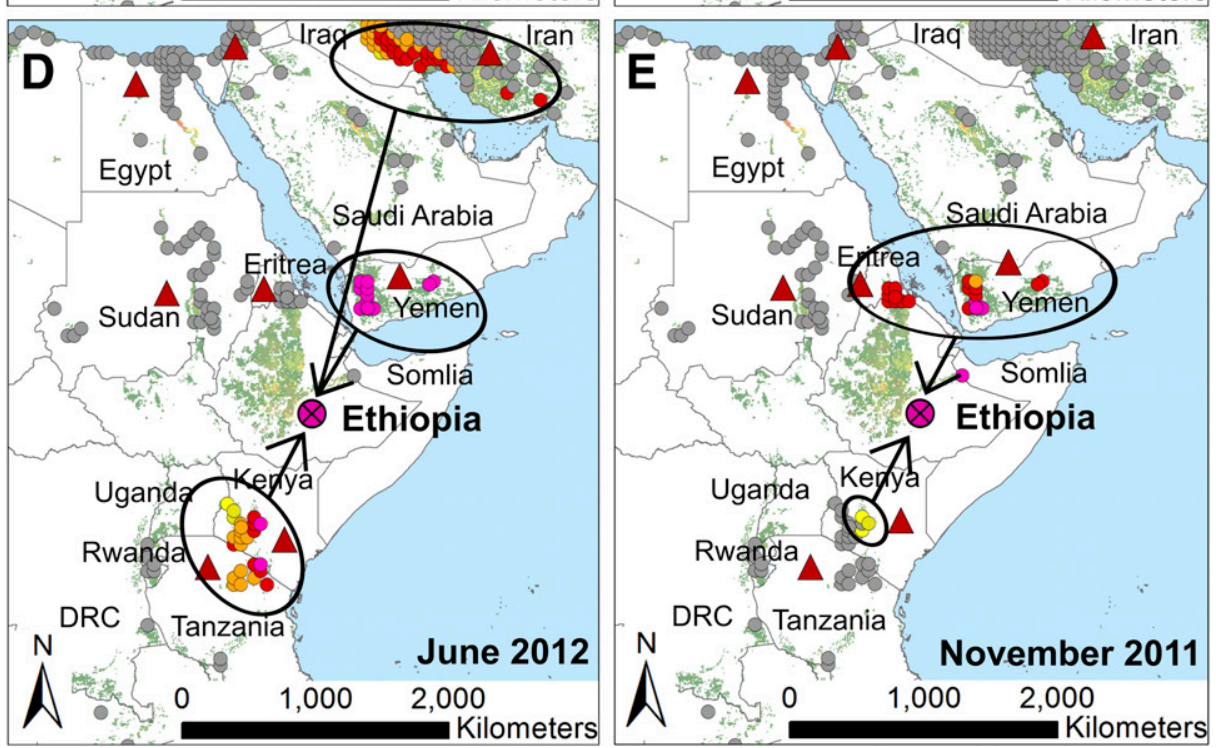

Fig. 3. Simulated monthly Puccinia graminis f. sp. tritici urediniospore deposition on the site of first detection of race TKTTF in Ethiopia from an array of possible sources. A, Example of one daily spore deposition plume. B and C, Seasonal variations of the airborne spore catchment area of the site of first detection, indicating wheat areas from which any spore transport to the site of first detection was possible (assuming a 3-day maximum spore lifetime). D and E, Monthly mean contributions to spore deposition on the site of first detection from all potential sources outside of Ethiopia in countries with a main wheat season that overlaps the wheat season in Ethiopia. In the absence of data on wheat stem rust outbreaks at all potential sources, we define the same constant source strength for all potential sources, to localize those from which atmospheric transport was more likely relative to other potential sources. 
years (2003 to 2016) from a single source in each of the following countries: Yemen, Eritrea, Kenya, Tanzania, and Iran. Whereas, in previous sections, we used an arbitrary constant source strength and restricted the analysis to relative proportions of spore deposition from different potential sources, in this section, we use order of magnitude estimates of real-life spore canopy escape rates at sources for different outbreak scenarios, denoted as $N_{\text {outbreak }}$. The variable $N_{\text {outbreak }}$, in units of number of spores released per day per source, is obtained by linear scaling of values reported in field experiments (Roelfs and Bushnell 1985; Aylor 1986), for different cases of infected area, severity, and incidence. In particular, we simulate spore dispersal for four different what-if scenarios of disease outbreaks at potential sources: (i) very small outbreak (with about a 1-hectare infected area and 5\% severity and incidence): $N_{v \text { s.small }}=5 \times 10^{9}$; (ii) small outbreak (with about a 10 hectare infected area and $15 \%$ severity and incidence): $N_{\text {small }}=5 \times 10^{11}$; (iii) moderate outbreak (with a $10^{2}$ to $10^{3}$-hectare infected area and 15 to $50 \%$ severity and incidence): $N_{\text {moderate }}=5 \times 10^{13}$; (iv) strong outbreak (with a $10^{4}$-hectare infected area and $50 \%$ severity and incidence): $N_{\text {strong }}=5 \times 10^{15}$. For each what-if outbreak scenario, we analyze the following spore deposition quantities on the wheat areas in the $30 \times$ $30 \mathrm{~km}^{2}$ area around the site of first detection of TKTTF in the Bale zone of Ethiopia: (i) the number of spore deposition days per month (with $>1$ spore/day]) and (ii) the median deposition amount per deposition day (Fig. 5; Table 2).

Our results show that, despite large daily variations of long-distance dispersal, there are strong and consistent seasonal (monthly) differences in spore transport from source countries, such as, for example, Kenya or Yemen, into Ethiopia (Fig. 5, for a moderate outbreak at sources). The number of deposition days as well as the median deposition amount per deposition day from West Yemen to the Bale zone are higher than from any other potential source country during most months. Hence, for comparable outbreaks in different source countries, the risk of incursion from Yemen is greatest. Note that, in general, it is not necessarily the case that a higher number of spore deposition days between two countries, along route $\mathrm{X}$, compared with two other countries, route Y, implies a higher total number of transported spores (i.e., a higher pathogen load) along route $\mathrm{X}$, because deposition amounts vary highly nonlinearly over several orders of magnitude. For example, one may distinguish the following risk scenarios: high frequency and high pathogen load in June from Yemen compared with medium frequency and high pathogen load in November from Yemen and high frequency but medium pathogen load in August from Kenya (Fig. 5).

The results for different outbreak scenarios are summarized in Table 2. There is a notably high risk of spore transmission from the highlands in West Yemen over the Red Sea into the wheat fields in the Bale zone of Ethiopia during June. Even for very small or small outbreaks (with about a 1- to 10-hectare infected area at about 5 to $15 \%$ severity and incidence) simulations predict viable spore transmission on more than $50 \%$ of release days (with a median spore deposition amount per deposition day of about $10^{2}$ to $10^{4}$ spores/day). Also, there is a considerable risk of spore transport from Kenya during June, July, and August, even for small outbreaks. On the other hand, in November, even in the case of a localized epidemic outbreak in Kenya (with $10^{4}$ hectares of infected wheat fields and $50 \%$ severity and incidence) viable spores are transported to the Bale zone only on about $2 \%$ of the release days. Table 2 provides a reference to inform the timing of early-warning surveys to prepare for deployment of control measures in Ethiopia in response to outbreaks of different sizes in potential source countries for $P$. graminis f. sp. tritici spore incursion.

\section{DISCUSSION}

Likely source origin of race TKTTF in Ethiopia. For both incursion during the belg season (June 2012) and incursion during the previous meher season (September through November 2011), our results indicate wheat fields in West Yemen as the most likely origin of TKTTF in Ethiopia (Figs. 2 and 3D and E). Eritrea constitutes an additional but less likely source, and we also find evidence for the possibility of direct incursion from sources in the Middle East (Iraq and Iran) and from countries in the southern Rift Valley (Kenya and Tanzania). Our results are consistent with (limited) available data from field sampling and phylogenetic analysis; the TKTTF isolates from Ethiopia are genetically similar to those from several countries in the Middle East as well as to samples collected in Yemen and Sudan (genetic clade IV-A.1; L. Szabo, personal communication), indicating that TKTTF spread from the Middle East southwards into the East African Rift Valley. A plausible hypothesis is that TKTTF first spread from Iran (where it was first detected in 2010) to Yemen (where it remained undetected until 2014), and then, further from Yemen into Ethiopia. It is feasible that TKTTF remained undetected in Yemen before detection in Ethiopia, because the number of available survey data from Yemen is very low. It should be noted again that humanmediated incursion cannot be absolutely ruled out, but circumstantial evidence around the spread of TKTTF and the location of the detection sites indicate that it is less likely than aerial dispersion in this case study.

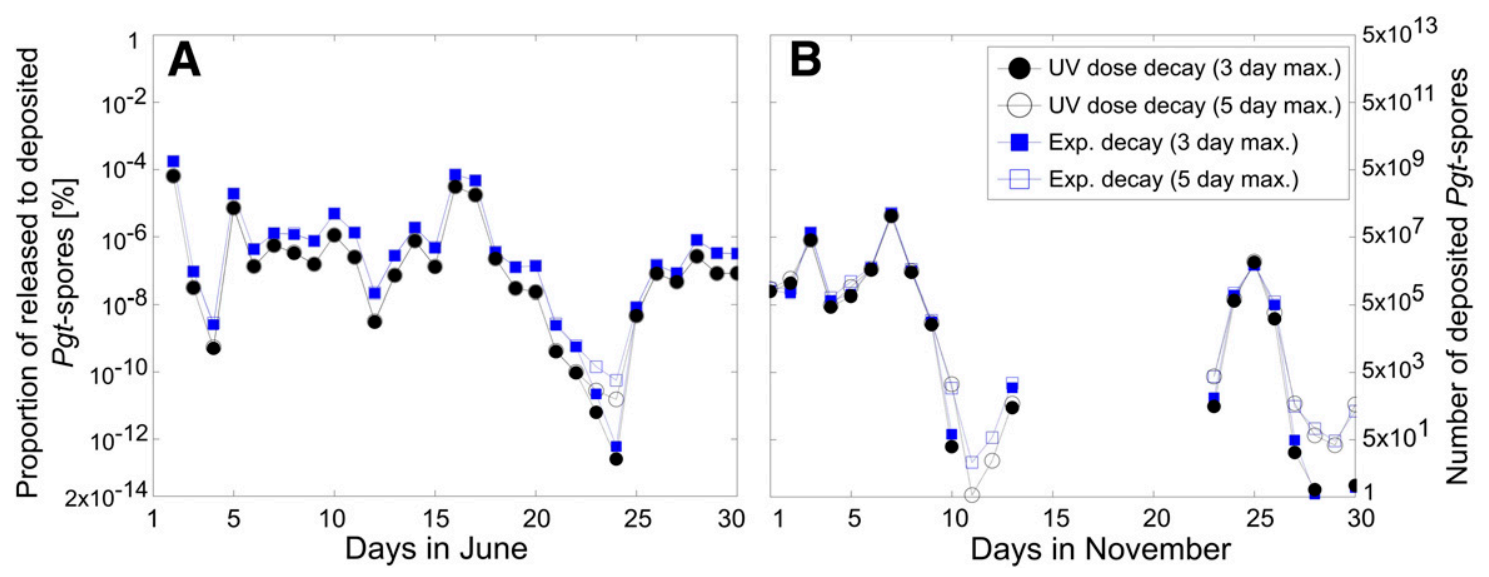

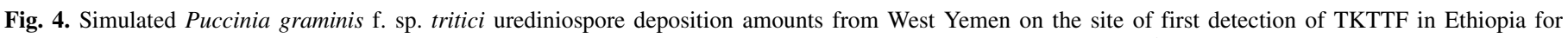

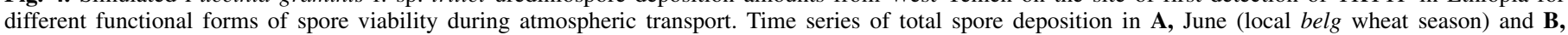

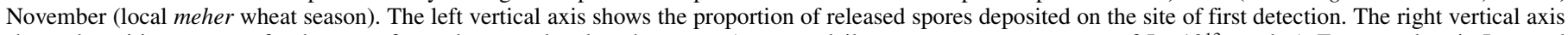

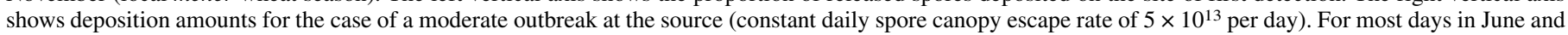

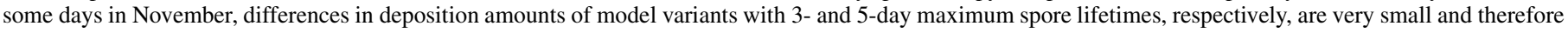
only partly visible in the illustration. 
LPDM simulations as a tool for source-localization. Despite the availability of three-dimensional backward modes in LPDMs, to our knowledge, these have not previously been used in the field of plant epidemiology; in a recent review by Schmale and Ross (2015), stochastic backward trajectories are discussed, but only in terms of single release altitudes and two-dimensional advection. A number of recent studies regarding fungal pathogens have used a low number $(<100)$ of mean backward trajectories and one release height to infer likely origins (Fernández-Rodríguez et al. 2015; Grinn-Gofroń et al. 2016; Sadyś, et al. 2014; Skjøth et al. 2009). Similar approaches are also found in related fields of other biological particulates (Hernández-Ceballos et al. 2011, 2014). While these approaches are useful for certain atmospheric conditions (notably relatively stable laminar flow), they neglect threedimensional turbulence and vertical wind shear. In particular, mean trajectory modeling approaches imply a number of (over)simplifying assumptions. First, using a single (or very few) trajectory assumes that turbulent transport processes can be realistically represented by following single air parcels in turbulent airflow. Due to the complexity of turbulent transport, it is known that this can lead to completely unreliable results; for example, in a recent study, Burgin et al. (2013) show that using only three backward trajectories leads to incorrect inferences about likely origins of a windborne livestock disease. Second, the use of mean (instead of stochastic) trajectories assumes that the effects of molecular diffusion and unresolved turbulent variations of the wind velocity field can be neglected. This can lead to large differences between mean trajectories and actual atmospheric transport processes (Lin 2013; Stohl et al. 2002). Third, release of tracer particles from single altitudes in backward simulations chosen to represent the altitude from which deposition may have occurred assumes homogeneous vertical wind profiles. But horizontal wind direction can vary strongly with altitude above the ground surface, even pointing in opposite directions. Our results for different release altitudes in the vertical atmospheric column above the first detection site clearly show that vertical wind shear can have very strong effects on the origin predicted by backward simulation (Fig. 1). At other times
(Fig. 2), there is little vertical wind shear and a single representative altitude leads to useful approximations. This emphasizes that the appropriate complexity of dispersal models depends on casespecific atmospheric conditions.

It is widely accepted, however, that LPDMs generally outperform simpler mean trajectory, box, or Gaussian plume models (Lin 2013; Stohl et al. 2002). In forward mode, LPDMs can be used as a tool for source localization by defining a large array of possible sources and simulating release, transport, loss of viability, and deposition on the target. The possibility of using large numbers of source locations in time-forward LPDM simulations conducted on advanced computing resources allows for great flexibility in the application of dispersal models to analyze a range of scenarios. Lagrangian models have been widely used with a small number of sources at canopy and field scales, both in simulation as well as more analytically and in combination with field measurements (see e.g. Aylor and Flesch 2001). However, for regional and continental scales, only a few studies of fungal spore dispersal have been reported using state-of-the-art LPDMs; these made use of NAME and HYSPLIT (Kim and Beresford 2008; Olivera et al. 2015; Pan et al. 2006; Wang et al. 2010).

Functional form of spore viability during atmospheric transport. The relatively small effect of different spore-viability models on deposition quantities at the site of first detection for different source locations and months of the year (Fig. 4) shows that a simple, time-dependent viability function can be an appropriate simplification if one aims at a parsiminous model for viability. Large variations of the meteorological variables, such as cloud cover, that influence spore viability, often occur on shorter time scales than the total transport time of spores. A simple timedependent scheme can, therefore, capture the average loss of viability with a level of accuracy, which may be sufficient, depending on the aim of simulations. On the other hand, the new UV dose-dependent scheme introduced here is more realistic and can account for more extreme scenarios, such as, for example, spore transport under entirely clear sky conditions for the entire duration of atmospheric transport. In general, the effect of the functional

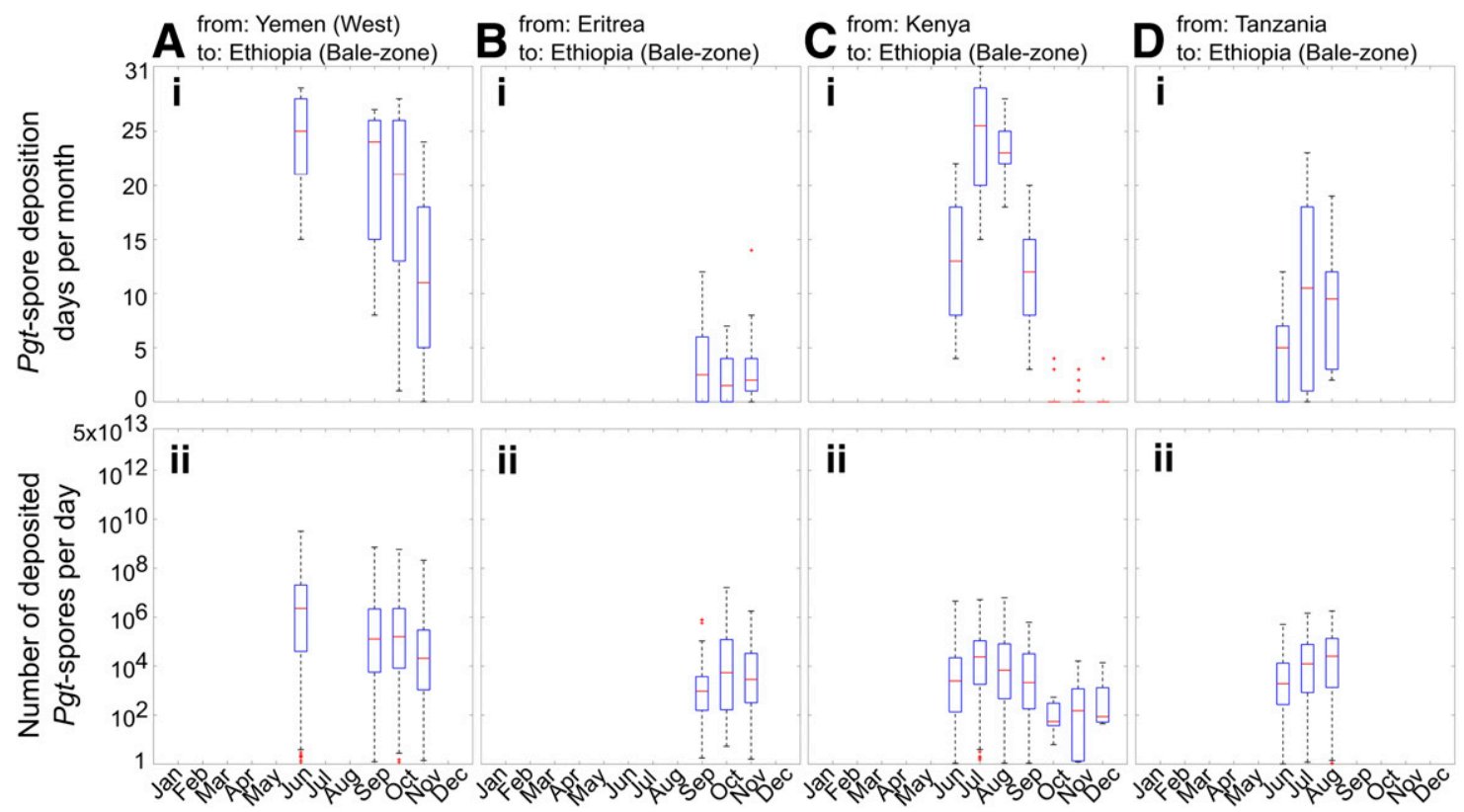

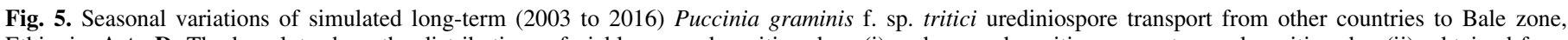

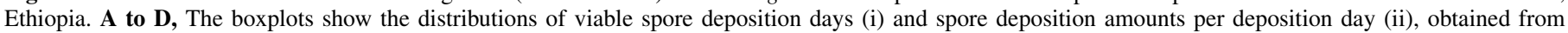

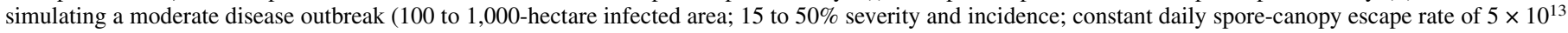

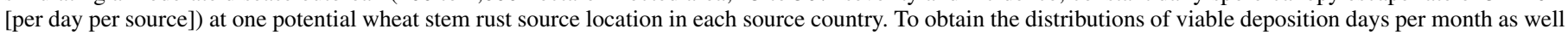

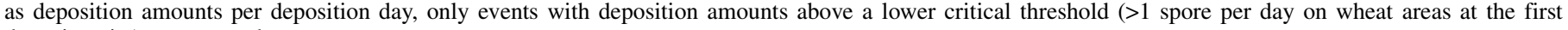
detection site) are counted. 
form of spore viability on total deposition amounts depends on the travel time between release and deposition as well as on the input meteorology. In previous work, the viability of other rust spores, causing soybean rust, has been measured experimentally and results have been implemented into the Integrated Aeriobiology Modeling System (IAMS) (Isard et al. 2006). For P. graminis f. sp. tritici spores, on the other hand, the available experimental data are sparse, which is a limiting factor for the accuracy of our spore viability model. The higher sensitivity of $P$. graminis f. sp.tritici spores to UV radiation at high relative humidities, as shown in (Schwinghamer 1958), has an important consequence for assessments of meteorological conditions that are conducive for longdistance transport, i.e., P. graminis f. sp. tritici spore transport below clouds (but not in clouds) is particularly suitable for very longdistance transport events.
Long-term seasonal trends of airborne pathogen inflow into Ethiopia. The results of simulations across multiple years conducted in this study (Fig. 5; Table 2) show strong seasonal trends in dispersal patterns. These, in turn, allow the identification and ranking of different countries as potential sources for incursion of exotic races of $P$. graminis f. sp. tritici into sub-Saharan Africa's largest wheat-producing country. The consistency of seasonal trends among years suggests that the seasonal inflow pattern identified for the case of TKTTF in 2011 to 2012 (Figs. 1, 2, and 3) is representative of inflow patterns into Ethiopia in other years. The larger extent of the airborne catchment area in June through August (Fig. 3) implies a particularly high potential of inoculum inflow, which can then act as a reservoir and inoculum source for the main meher wheat season in Ethiopia. This, we hypothesize, may have contributed to recurrent wheat rust epidemics during recent decades in Ethiopia, because it

TABLE 2. Long-term trends (2003 to 2016) of simulated monthly long-distance airborne Puccinia graminis f. sp. tritici urediniospore transport to the Bale zone in Ethiopia ${ }^{a}$

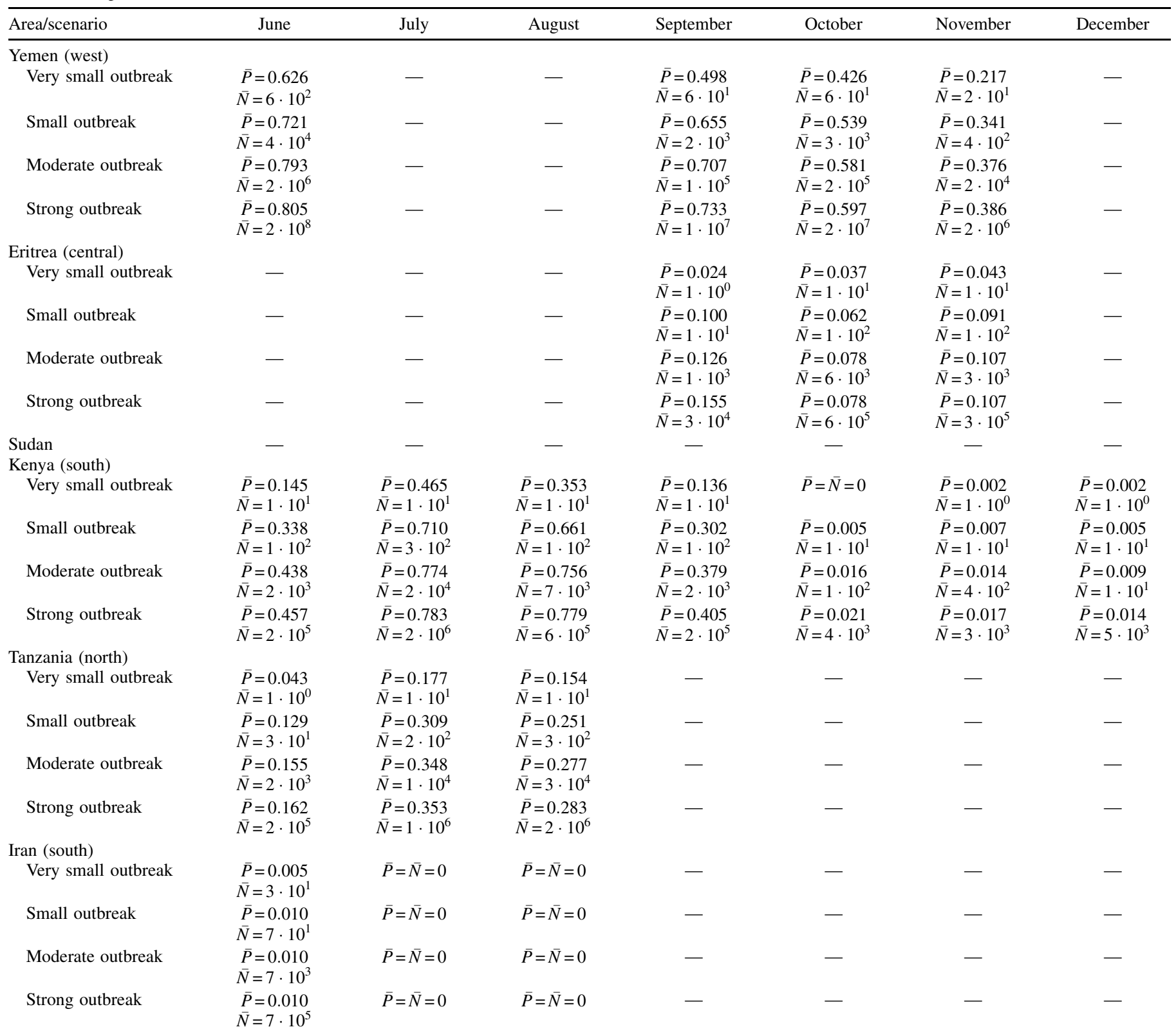

a Spore transmission quantities are summarized for four different 'what-if' scenarios of wheat stem rust outbreaks with varying spore canopy escape rate at the source (very small: $N_{v, \text { small }}=5 \cdot 10^{9}$; small: $N_{\text {small }}=5 \cdot 10^{11}$; moderate: $N_{\text {moderate }}=5 \cdot 10^{13}$; strong: $N_{\text {strong }} 5 \cdot 10^{15}$ ). Months with no overlap of the main wheat season in the source country and in Ethiopia are marked with —; there was no such overlap in January through May. For months of overlapping main wheat seasons at source and target, two spore transmission quantities are provided: (i) the mean proportion of release days with viable spore deposition ( $>1$ spore day) on wheat areas at the site of first detection, denoted as $\bar{P}$, and (ii) the median deposition amount (number of deposited spores) per deposition day on wheat areas at the first detection site, denoted as $\bar{N}$. 
indicates a large potential for inflow of pathogens from external sources.

The information about the risk of exotic $P$. graminis f. sp. tritici spore dispersal into Ethiopia (Table 2) may be used to assess future risk from neighboring countries and inform the timing of surveillance and control. However, it is important to recall that these results are probabilistic long-term trends, which cannot directly be extrapolated to future years. Rather, these should be interpreted as follows. The consistent seasonal trends in combination with the estimates of certain what-if scenarios of source strength necessary for spore deposition quantities above a critical lower threshold allow a narrowing of the ranges of probabilities of long-distance spore incursion in different months from different sources for different outbreak scenarios. We see a large potential in combining these long-term estimates with short-term forecasting of spore dispersal from the latest detection sites in the field.

Application of spore-dispersal modeling in national wheat rust early warning systems. In the last two wheat seasons, a semioperational spore-dispersal forecast model pipepline has been developed for NAME by Cambridge University and the Met Office, U.K. The system ran successfully on a daily basis, providing 7-day advanced forecasts of rust dispersal from field-sites of observed rust appearance in Ethiopia. This was done in the context of the prioritization given to controlling wheat rust outbreaks by the Ethiopian government and partners, who are developing and implementing a wheat rust early warning and management plan. Field survey data are obtained in near-real time through an electronic survey application and are fed into the forecast model. Dispersal outputs are used by CIMMYT and Ethiopian institutions to inform and target control or scouting activities in areas of highest risk of spore incursion. Novel, crowd-sourcing approaches through automated mobile phone surveys are also being piloted as potential additional sources of information on initial rust outbreaks and validation of model outputs. Initial indications of the application of LPDM for rust forecasting appear promising. Further development of the forecasting system is ongoing.

Conclusions. This paper shows that using high-performance computing, finely resolved global meteorological data, and a stateof-the-art LPDM adapted to P. graminis f. sp. tritici spores can greatly improve knowledge of regional- and continental-scale spore movements. The analyses provide a basis for better advanced warning and risk assessment should virulent new races be detected in potential source countries. While high-performance computing power and improved dispersal models offer these new opportunities, current understanding of atmospheric dispersal of fungal spores is limited by the sparsity of field experimental data. For example, there are no data available on exact spore release and deposition rates for an array of sources and targets distributed on regional and continental scales. This is different from that on small spatial scales (field and local scales), for which a number of informative and very promising studies have been conducted that combine drone measurements with dispersal simulations (Aylor et al. 2011). One of the challenges for future work will be to combine large-scale simulation studies, as presented here, with empirical observations on regional and continental scales. In related fields of atmospheric transport of particulates, such as, for example, volcanic ash, satellite images of ash clouds, airplane sampling, and exact field measurements of deposition rates from an array of samplers distributed over large spatial scales (regions and continents) are available and have been used to validate dispersal models. Comparable approaches for rust spore dispersal using aircraft sampling would greatly enhance our understanding of regional and continental scale fungal spore dispersal. Almost 90 years ago, the Cambridge mycologist D. Weston embarked the British Airship R100 on its maiden flight, and, 2,000 feet above sea level, he opened a window, stretched out a Petri dish, and became one of the first to pioneer aerial spore catchments. The progress in the field of high-performance computing, numerical weather-prediction models, and LPDM simulations promises that we are now able to predict what we would catch, even on transatlantic flights over regional and continental scales.

\section{ACKNOWLEDGMENTS}

M. Meyer and C. A. Gilligan gratefully acknowledge financial support from the Bill \& Melinda Gates Foundation, the Biotechnology and Biological Sciences Research Council (BBSRC), and the Friedrich-EbertStiftung. D. P. Hodson received financial support from the Bill \& Melinda Gates Foundation and the U.K. Department for International Development. Logistical support from the U.K. Met Office and CIMMYT is gratefully acknowledged. We are also grateful to the many in-country field scientists who have contributed information on wheat cropping patterns and disease surveys, as well as to E. Turner, from the Met Office, for providing the UK Met Office's Unified Model test runs for comparison of UV fields, and to L. Szabo, United States Department of Agriculture Agricultural Research Service, for providing the most recent phylogenetic results of TKTTF samples. We thank the members of the Epidemiology and Modelling group in Cambridge for useful discussions.

\section{LITERATURE CITED}

Aylor, D. E. 1986. A framework for examining inter-regional aerial transport of fungal spores. Agric. For. Meteorol. 38:263-288.

Aylor, D. E., and Flesch, T. K. 2001. Estimating spore release rates using a Lagrangian stochastic simulation model. J. Appl. Meteorol. 40:1196-1208.

Aylor, D. E., Schmale, D. G., Shields, E. J., Newcomb, M., and Nappo, C. J. 2011. Tracking the potato late blight pathogen in the atmosphere using unmanned aerial vehicles and Lagrangian modeling. Agric. For. Meteorol. 151:251-60.

Burgin, L. E., Gloster, J., Sanders, C., Mellor, P. S., Gubbins, S., and Carpenter, S. 2013. Investigating incursions of bluetongue virus using a model of long-distance Culicoides biting midge dispersal. Transbound. Emerg. Dis. 60:263-72.

Calbó, J., Pagès, D., and González, J.-A. 2005. Empirical studies of cloud effects on UV radiation: A review. Rev. Geophys. 43:RG2002.

Davies, T., Cullen, M. J. P., Malcolm, A. J., Mawson, M. H., Staniforth, A., White, A. A., and Wood, N. 2005. A new dynamical core for the Met Office's global and regional modelling of the atmosphere. Q. J. R. Meteorol. Soc. 131:1759-82.

Draxler, R., Arnold, D., Chino, M., Galmarini, S., Hort, M., Jones, A., Leadbetter, S., Malo, A., Maurer, C., Rolph, G., Saito, K., Servranckx, R., Shimbori, T., Solazzo, E., and Wotawa, G. 2015. World Meteorological Organization's model simulations of the radionuclide dispersion and deposition from the Fukushima Daiichi nuclear power plant accident. J. Environ. Radioact. 139:172-184.

Draxler, R., and Hess, G. D. 1997. Description of the HYSPLIT4 modeling system. Air Resources Laboratory, Silver Spring, MD.

Eversmeyer, M. G., and Kramer, C. L. 2000. Epidemiology of wheat leaf and stem rust in the central Great Plains of the USA. Annu. Rev. Phytopathol. 38:491-513.

Fernández-Rodríguez, S., Sadyś, M., Smith, M., Tormo-Molina, R., Skjøth, C. A., Maya-Manzano, J. M., Silva-Palacios, I., and Gonzalo-Garijo, A. 2015. Potential sources of airborne Alternaria spp. spores in south-west Spain. Sci. Total Environ. 533:165-76.

Foyo-Moreno, I., Vida, J., and Alados-Arboledas, L. 1999. A simple all weather model to estimate ultraviolet solar radiation (290-385 nm). J. Appl. Meteorol. 38:1020-1026.

Frederick, J. E., and Steele, H. D. 1995. The transmission of sunlight through cloudy skies: An analysis based on standard meteorological information. J. Appl. Meteorol. 34:2755-2761.

Gebre-Mariam, H., Tanner, D. G., and Hulluka, M. 1991. Wheat Research in Ethiopia: A Historical Perspective. Institute of Agricultural Research/CIMMYT, Addis Ababa, Ethiopia.

Grinn-Gofroń, A., Sadyś, M., Kaczmarek, J., Bednarz, A., Pawłowska, S., and Jedryczka, M. 2016. Back-trajectory modelling and DNA-based speciesspecific detection methods allow tracking of fungal spore transport in air masses. Sci. Total Environ. 571:658-69.

Hernández-Ceballos, M. A., García-Mozo, H., Adame, J. A., Domínguez-Vilches, E., Bolívar, J. P., De la Morena, B. A., Pérez-Badía, R., and Galán, C. 2011. Determination of potential sources of Quercus airborne pollen in Córdoba city (southern Spain) using back-trajectory analysis. Aerobiologia 27:261-76.

Hernandez-Ceballos, M. A., Soares, J., García-Mozo, H., Sofiev, M., Bolivar, J. P., and Galán, C. 2014. Analysis of atmospheric dispersion of olive pollen in southern Spain using SILAM and HYSPLIT models. Aerobiologia 30: 239-55.

Isard, S. A., Dufault, N. S., Miles, M. R., Hartman, G. L., Russo, J. M., De Wolf, E. D., and Morel, W. 2006. The effect of solar irradiance on the mortality of Phakopsora pachyrhizi urediniospores. Plant Dis. 90:941-945. 
Jones, A. R. 2013. User Guide for NAME. Met Office, Exeter, U.K. http:// www.metoffice.gov.uk/research/modelling-systems/dispersion-model

Jones, A. R., Thomson, D. J., Hort, M., and Devenish, B. 2007. The U.K. Met Office's next-generation atmospheric dispersion model, NAME III. Pages 580-589 in: Air Pollution Modeling and Its Application XVII. C. Borrego, and A.-L. Norman, eds. Springer, Boston.

Kim, K. S., and Beresford, R. M. 2008. Use of a spectrum model and satellite cloud data in the simulation of wheat stripe rust (Puccinia striiformis) dispersal across the Tasman Sea in 1980. Agric. For. Meteorol. 148: 1374-82.

Lin, J. C. 2013. Lagrangian modeling of the atmosphere: An introduction. Pages 1-11 in: Geophysical Monograph Series. J. Lin, D. Brunner, C. Gerbig, A. Stohl, A. Luhar, and P. Webley, American Geophysical Union, Washington, D.C.

Maddison, A. C., and Manners, J. G. 1972. Sunlight and viability of cereal rust uredospores. Trans. Br. Mycol. Soc. 59:429-43.

Mert, Z., Karakaya, A., Düsünceli, F., Akan, K., and Çetin, L. 2012. Determination of Puccinia graminis f. sp. tritici races of wheat in Turkey. Turk. J. Agric. For. 36:107-120.

Olivera, P., Newcomb, M., Szabo, L., Rouse, M. N., Johnson, J. L., Gale, S. W., Luster, D. G., Hodson, D., Cox, J. A., Burgin, L., Hort, M., Gilligan, C. A., Patpour, M., Justesen, A F., Hovmøller, M. S., Woldeab, G., Hailu, E., Hundie, B., Tadesse, K., Pumphrey, M., Singh, R. P., and Jin, Y. 2015. Phenotypic and genotypic characterization of race TKTTF of Puccinia graminis f. sp. tritici that caused a wheat stem rust epidemic in southern Ethiopia in 2013-14. Phytopathology 105:917-928.

Orr, G. F., and Trippets, W. C. 1972. Morphology and other physical characteristics of urediospores possibly related to aerodynamics and long range travel. Mycopathol. Mycol. Appl. 48:143-159.

Pan, Z., Yang, X. B., Pivonia, S., Xue, L., Pasken, R., and Roads, J. 2006. Long-term prediction of soybean rust entry into the continental United States. Plant Dis. 90:840-846.

Roelfs, A. P., and Bushnell, W. R. 1985. The cereal rusts, Vol. II. Diseases, Distribution, Epidemiology, and Control. Academic Press, Inc., New York.

Sadyś, M., Skjøth, C. A., and Kennedy, R. 2014. Back-trajectories show export of airborne fungal spores (Ganoderma sp.) from forests to agricultural and urban areas in England. Atmos. Environ. 84:88-99.

Schmale, D. G., and Ross, S. D. 2015. Highways in the sky: Scales of atmospheric transport of plant pathogens. Annu. Rev. Phytopathol. 53:591-611.
Schwinghamer, E. A. 1958. The relation of survival to radiation dose in rust fungi. Radiat. Res. 8:329-343.

Singh, R. P., Hodson, D. P., Huerta-Espino, J., Jin, Y., Bhavani, S., Njau, P., Herrera-Foessel, S., Singh, P. K., Singh, S., and Govindan, V. 2011. The emergence of $\mathrm{Ug} 99$ races of the stem rust fungus is a threat to world wheat production. Annu. Rev. Phytopathol. 49:465-81.

Singh, R. P., Hodson, D. P., Jin, Y., Lagudah, E. S., Ayliffe, M. A., Bhavani, S., Rouse, M. N., Pretorius, Z. A., Szabo, L. J., Huerta-Espino, J., Basnet, B. R., Lan, C., and Hovmøller, M. S. 2015. Emergence and spread of new races of wheat stem rust fungus: Continued threat to food security and prospects of genetic control. Phytopathology 105:872-84.

Skjøth, C. A., Smith, M., Brandt, J., and Emberlin, J. 2009. Are the birch trees in southern England a source of Betula pollen for north London? Int. J. Biometeorol. 53:75-86.

Stohl, A., Eckhardt, S., Forster, C., James, P., Spichtinger, N., and Seibert, P. 2002. A replacement for simple back trajectory calculations in the interpretation of atmospheric trace substance measurements. Atmos. Environ. 36:4635-4648

Wang, H., Yang, X. B., and Ma, Z. 2010. Long-distance spore transport of wheat stripe rust pathogen from Sichuan, Yunnan, and Guizhou in southwestern China. Plant Dis. 94:873-880.

Webster, H. N., Thomson, D. J., Johnson, B. T., Heard, I. P. C., Turnbull, K. 2012. Operational prediction of ash concentrations in the distal volcanic cloud from the 2010 Eyjafjallajökull eruption. J. Geophys. Res. Atmospheres 117:1-17.

White, J. W., Tanner, D. G., and Corbett, J. D. 2001. An agro-climatological characterization of bread wheat production areas in Ethiopia. http:// repository.cimmyt.org/handle/10883/1022. International Maize and Wheat Improvement Center (CIMMYT), México, D.F., México.

\section{AUTHOR-RECOMMENDED INTERNET RESOURCES}

FAO GIEWS country briefs. Food and Agriculture Organization of the United Nations (FAO) Global Information and Early Warning System (GIEWS) country briefs database: http://www.fao.org/giews/countrybrief

FAOSTAT database: www.fao.org/faostat

CIMMYT Rusttracker (2017). The International Maize and Wheat Improvement Center's RustTracker: http://rusttracker.cimmyt.org

MapSPAM (Spatial Production Allocation Model), v2.0: www.mapspam.info 